Estudos de Psicologia

1998, Vol 15, $\mathrm{n}^{\circ} 1,77-80$

\title{
Teoria da posse
}

\author{
Sebastião Elyseu Júnior \\ Pontifícia Universidade Católica de Campinas
}

Em nosso livro" Contribuições a uma teoria de personalidade" havíamos sugeri- do uma teoria da posse e já tínhamos esboçado alguns de seus pontos (EL YSEU - 1996).

Agora, expondo-a completamente, começamos afirmando que ela é complementar à teoria bowlbiana do apego na explicação do desenvolvimento da personalidade humana, pois ela também tem base etológica, isto é, está baseada em comporta- mentos instintivos (filogênicos), presentes não apenas em humanos mas também em outras espécies animais.

Naturalmente, esses comportamentos são acionados no indivíduo desde a sua mais tenra infância e as vicissitudes a que estão sujeitos no curso da própria vida estabelecem os possíveis padrões de conduta, normal ou patológicos.

Para a compreensão de uma teoria etológica há que se referir às condições ambientais favoráveis ou desfavoráveis à sobrevivência da espécie animal em questão.

Assim, a capacidade de uma população de aumentar em número, em condições ambientais favoráveis, isto é, o seu potencial biótico enfrenta a resistência do ambiente, que compreende a predação e o parasitismo a

Endereço para correspondência: Av. DI'. Moraes Salles, 1610, apto. 31, CEP 13010-002, Campinas, SP, Fone/Fax: (019) 252-7519.

que está sujeita, os efeitos climáticos, a competição intra e interespecífica e as limitações de espaço e alimento. Num ecossistema em equilíbrio, como observado num ambiente natural, o tamanho da população mantém-se relativamente estável como resultado do confronto entre esse potencial biótico e essa resistência do ambiente (SILVA JR. e SEZAR -1989).

Se considerarmos que em termos de conduta os animais pouco ou nada podem fazer contra os parasitas, os efeitos climáticos e as limitações de espaço e alimento, restam, como fatores de resistência ambiental, a predação e a competição intra e interespecífica.

Segundo BOWLBY (1969), no ambiente de adaptabilidade eoolutioa, algumas espécies animais, inclusive o homem, desenvolveram comportamentos instintivos de apego e de cuidar, como formas de se defender principalmente contra predadores. Pela sua Teoria do Apego, o comportamento de apego, existente no indivíduo, consiste em buscar proximidade da figura de apego (em geral, os pais) com o fim de proteção pessoal; o comportamento de cuidar, existente na figura de apego, consiste em oferecer cuidado ao indivíduo com o fim de protegê-lo. Ambos os comportamentos, quer em interação diádica harmoniosa quer não, têm significativa importância para o desenvolvimento da personalidade, estabelecendo padrões de conduta, normal ou patológicos, amplamente demonstrados por pesquisas 
experimentais citadas em suas obras e de outros autores.

Mas, que comportamentos foram desenvolvidos no indivíduo para que ele pudesse realizar a competição intra e interespecífica?

$\mathrm{Na}$ competição intraespecífica existe a questão da territorialidade, que consiste na posse de um espaço delimitado, em geral por um macho que o defende de outro da sua espécie; mas, que pode ser defendido também pelo casal ou pelos membros do grupo.

Segundo DETHIER e STELLAR (1970), a territorialidade:

"com certeza facilita o acasala- mento e o cuidado dos jovens, mas também fornece solução habitual dos problemas de alimentação e manutenção de abrigo".

SILVA JR. e SEZAR (1989) afirmam que:

"a territorialidade foi observa- da em animais muito diferentes como macacos, focas, libélulas, cervos, castores, alguns lagartos e em grande número de espécies de aves e de peixes".

Segundo ORR (1966), entre os mamíferos, os machos podem usar o território unicamente para a reprodução e não para a proteção dos filhos e da fêmea; afirma, mais adiante, que a maioria dos primatas vive em grupos sociais com território definido, podendo ter um macho dominante além de outros sub dominantes, fêmeas e filhotes.

Outra questão, na competição intraespecífica, é a luta entre machos pela posse da fêmea; na época da reprodução, ela é freqüentemente observada entre as mais varia- das espécies como a dos gorilas, dos cabritos monteses, dos bisões, dos delfins, dos cangurus etc.

Outra questão ainda é que pela própria condição heterotrófica, os animais, competindo intra ou interespecificamente, buscam o seu alimento no ambiente, já que não o sintetizam como fazem os vegetais.

Este alimento, muitas vezes, são outros animais que precisam ser caçados ou pescados, isto é, possuídos pelo comporta- mento predatório; aqui, diferentemente da situação em que o indivíduo precisa se de- fender dos predadores, é ele próprio o predador.

Mas, a posse do alimento não é realizada apenas pelo comportamento predatório; também é realizada pelos comporta- mentos de coleta e armazenagem, observa- dos especialmente nos roedores. Há, ainda, animais como os ursos e os cães que, quando saciados, escondem o seu alimento enterrando-o para posterior usufruto.

Os comportamentos de luta e de fuga não servem apenas ao fim de defesa pessoal, servem também à posse: na luta, pela posse do alimento ou em defesa da posse dele, tal como nos casos da posse do território e da fêmea; na fuga, carregando-o.

Observa-se ainda a disputa pela posse do alimento pelo comportamento de preensão; e, em todos os casos, o alimento possuído pode servir tanto ao próprio indivíduo quanto à sua prole.

Então, os comportamentos predatórios de caça e pesca, os comportamentos de 
Teoria da posse

coleta, de armazenagem e de esconder o alimento, o comportamento de fuga com o alimento, o comportamento de luta pela posse ou em defesa da posse do território, do alimento e da fêmea, e o comportamento de preensão são algumas formas específicas de o animal poder ter à sua disposição estes elementos ambientais para a própria sobrevivência, da prole e, afinal, da espécie.

Como sobrevivência não está correlacionada com eventualidade, esses comportamentos específicos são instintivos (filogênicos) e portanto ambientalmente estáveis, e, a eles, podemos dar genericamente o nome de comportamento de posse.

Melhor definido, o comportamento de posse tem como metafixada tornar ou manter à disposição do indivíduo figuras de posse com o fim de imediato ou de oportuno usufruto próprio ou da prole, sendo a figura de posse qualquer elemento ambienta! que atenda a este fim e gere o sentimento de posse.

Tal como outros comportamentos instintivos corrigidos para a meta, o de posse é ativado e finalizado basicamente por inputs sensoriais e mediado por sistemas de controle.

O comportamento de posse, pelas evidências observadas, existe na espécie humana mesmo porque ela também se desenvolveu num ambiente de adaptabilidade evolutiva semelhante ao dos outros animais citados e, por ser de alto valor biológico, as vicissitudes a que este comporta- mento está sujeito devem ter fundamental importância para o desenvolvimento da personalidade, tal como têm as relativas ao comportamento de apego.

As observações da conduta humana na clínica e fora dela sugerem a existência

dos seguintes padrões de posse: a posse segura, a posse ansiosa e a posse ciumenta.

Ao que tudo indica, a melhor dimensão para se estabelecer estes padrões de posse parece ser a segurança da posse, tal como a do apego, cuja medida está nas manifestações de comportamentos exploratórios; mas, tudo isso requer pesquisas experimentais bem conduzidas para a sua confirmação, o que está sendo providenciado.

Pelas observações, quando o indivíduo, através do comportamento de posse, torna ou mantém a figura de posse à sua disposição ele experimenta um sentimento de posse e um sentimento de segurança pela provisão - é o que podemos chamar de posse segura à semelhança do apego seguro, pela realização do comportamento de apego, isto é, pela reunião do indivíduo com a sua figura de apego, que lhe gera um senti- mento de apego e, outro, de segurança pela proteção.

Quando há a ameaça de perda da posse (e do usufruto), isto é, há a ameaça de indisponibilidade da figura de posse por ela mesma, o indivíduo experimenta ansiedade do mesmo modo que ocorre na separação (inacessibilidade temporária) ou na ameaça de separação (ameaça de inacessibilidade) da figura de apego - é a posse ansiosa.

No entanto, quando a ameaça de in- disponibilidade da figura de posse (privação ou desprovisão) é feita por uma terceira figura (ameaçadora), além da ansiedade, o indivíduo experimenta ciúme da sua figura de posse - é a posse ciumenta.

No penúltimo caso, quando há ameaça da perda da posse pela própria figura de posse, é ativado o comportamento de posse, maniiestadopelas tentativas de manutenção da posse dela e, no último caso, 
quando a ameaça é feita por uma terceira pessoa, o comportamento é maniiestado pela preensão da figura de posse, ou pela fuga, carregando-a, ou pela luta para a sua manutenção.

Do mesmo modo que surge o desapego (desativação do comportamento de apego) como defesa contra a ansiedade de perda da figura de apego (protetora) surge o desprendimento (desativação do comportamento de posse) como defesa contra a ansiedade de perda da figura de posse.

Essa defesa (desprendimento) parece surgir também por perdas repetidas; além disso, o indivíduo pode tornar-se desprendido como defesa contra a culpa pela posse ou como reação contra ser forçado a tomar conta do que é seu ou, ainda, ser criado impedido de ter posse de algo.

Finalizando, queremos acrescentar que havíamos sugerido (ELYSEU JR. 1996) a discriminação de figuras de relação no mo- delo funcional bowlbiano, pela sua importância para uma compreensão mais específica dos fenômenos neuropsíquicos. O conceito de figura de relação, postulado por nós, é o de que ela é funcionalmente específica para gerar determinado afeto e, eventualmente, para atender algum desejo ou comportamento.

Assim, na perda da figura de apego o indivíduo fica desprotegido e se sente ansioso; na perda da figura de posse ele fica privado ou desprovido dela e se sente empobrecido; e, na perda da figura querida (amada) ele se sente entristecido (deprimi- do). Exemplificando, diremos que se alguém se separa de um segurança (figura de

apego) está desprotegido e se sente ansioso da mesma maneira que se ele perde um amuleto (figa, agnudei etc.). Não é o mesmo que acontece na perda de um isqueiro, de um relógio, de um funcionário etc. (figuras de posse) por cuja privação o indivíduo se sente empobrecido; porém, se este relógio é de estimação (figura amada) ele se sente entristecido além de empobrecido, dada a possibilidade de combinação de figuras de relação ativadas num só objeto, situação ou pessoa. Assim, se há combinação de figuras contraditórias ativadas, há a ambivalência (sabotamento mútuo); caso contrário, como é o do exemplo dado, há o re forçamento.

\section{Referências Bibliográficas}

Bowlby, J. (1969). Attachment and loss (vol. 1: Attachment), London, Hogarth Press.

Dethier,V.G. e Stellar, E. (1970). Animal behauior, Englewood Cliffs, Prentice-Hall Inc.

Elyseu Jr., S. (1996). Contribuições a uma teoria de personalidade, Campinas, Editora Alínea.

Orr, R. T. (1966). Vertebrate Biology, Philadelphia, W. B. Saunders Co.

SilvaJr., C. e Sezar, S. (1989). Biologia 3, São Paulo, Atual Editora Ltda. 